\title{
Performance analysis of 20 Pole 1.5 KW Three Phase Permanent Magnet Synchronous Generator for low Speed Vertical Axis Wind Turbine*
}

\author{
Shahrukh Adnan Khan ${ }^{1}$, Rajprasad K. Rajkumar ${ }^{1}$, Rajparthiban K. Rajkumar ${ }^{1}$, Aravind CV ${ }^{2}$ \\ ${ }^{1}$ Faculty of Engineering, University of Nottingham Malaysia Campus, Jalan Broga, Semenyih, Malaysia \\ ${ }^{2}$ School of Engineering, Taylor's University, Selangor, Malaysia \\ Email:kecx1msa@nottingham.edu.my, Rajprasad.Rajkumar@nottingham.edu.my, \\ Rajparthiban.Rajkumar@nottingham.edu.my aravindcv@ieee.org
}

Received April, 2013

\begin{abstract}
This paper gives performance analysis of a three phase Permanent Magnet Synchronous Generator (PMSG) connected to a Vertical Axis Wind Turbine (VAWT). Low speed wind condition (less than $5 \mathrm{~m} / \mathrm{s}$ ) is taken in consideration and the entire simulation is carried in Matlab/Simulink environment. The rated power for the generator is fixed at $1.5 \mathrm{KW}$ and number of pole at 20. It is observed under low wind speed of $6 \mathrm{~m} / \mathrm{s}$, a turbine having approximately $1 \mathrm{~m}$ of radius and $2.6 \mathrm{~m}$ of height develops $150 \mathrm{Nm}$ mechanical torque that can generate power up to $1.5 \mathrm{KW}$. The generator is designed using modeling tool and is fabricated. The fabricated generator is tested in the laboratory with the simulation result for the error analysis. The range of error is about 5\%-27\% for the same output power value. The limitations and possible causes for error are presented and discussed.
\end{abstract}

Keywords: Vertical Axis Wind Turbine; Three Phase Multi-pole permanent Magnet Synchronous Generator; Low Wind Speed; Modeling; Performance Analysis

\section{Introduction}

Various countries worldwide are aware of the fact that the past and current trends of energy system are not sustainable and a solution needs to be drawn to secure the world energy from a drastic falling. One of the sources that can replace the current trend is surely wind energy which greatly depends on the availability of the wind resource. Areas found around the equatorial regions tend to have low wind speeds. For example, Malaysia currently has an average wind speed of 2-3 m/s, with higher wind velocity in the east coast of west Malaysia [1]. For a typical horizontal axis wind turbine to run and generate power, a wind speed of at least $5 \mathrm{~m} / \mathrm{s}$ is required [2]. A speed that is less than $5 \mathrm{~m} / \mathrm{s}$ is not sufficient to turn the turbine. Another predicament is that these regions face unsteady multi-directional winds making HAWT totally incompatible in such areas. The vertical axis wind turbine (VAWT) on the other hand is appropriate for such regions due to its ability to capture wind energy at any direction. Also, the use neodymium magnets for suspension at the bottom surface assist attaining zero friction, which helps counter the low wind speed problem [2].

Conventional generators can be replaced with Permanent Magnet Synchronous Generator (PMSG) using multi- pole stator arrangement. The multi-pole stator arrangement can be configured to generate high voltage at low revolution, and high current at faster speeds. The stator is designed to produce negligible cogging torque therefore causing the generator to start up and cut-in at low speeds to produce high current [3]. One significant advantage of PMSG, is that it is much lighter, smaller in size, and uses less constructional material so lowering cost and hub size [2][3]. Although a number of researches in the area of VAWT and PMSG are carried through separately, few attempts were taken to build a system together that work more efficiently at low wind speed. Moreover, there is a significant lack of research to find an optimal multi-pole PMSG for a VAWT with a fixed swept area which is realistic to work in those low wind speed countries. The main objective of this paper is to simulate and investigate the response of a permanent synchronous generator of a vertical wind turbine under different operating scenario through in Matlab/ Simulink environment.

\section{Methodology}

The equations of VAWT and PMSG are implemented in SIMULINK and a graphical user interface is developed to aid users in designing the VAWT. For the modeling 
part, at first the turbine section is designed. The radius, wind speed, the swept area, the power coefficients and pitch angles are made as variables. After designing the turbine, simulation is performed and the data is compared with the analytical design value to ensure the accuracy of the turbine design. Later, with the changing parameters, the torque and the power output values are observed and optimal design parameters are derived. The simulation of PMSG is carried for different values of mechanical torque and speed for the pre selected values from the simulation and lastly the load voltage, current and power are measured for evaluation. The generator design is developed and is experimentally tested and compared with the simulation data. Figure 1 show the methodology used in this approach.

\section{Modelling}

\subsection{Design of VAWT}

The design of VAWT derived from the work stated in [5-12].

The aerodynamic power $\mathrm{P}_{\mathrm{m}}$ of the turbine is given by the Equation 1.

$$
\mathrm{P}_{\mathrm{m}}=\mathrm{C}_{\mathrm{p}}(\lambda) \frac{1}{2} \rho \mathrm{A \textrm {U } _ { \mathrm { w } }}{ }^{3}
$$

Here, $\boldsymbol{P}$ is the air density in $\left(\mathrm{kg} / \mathrm{m}^{3}\right)$ at normal temperature, $\mathrm{A}$ is the area covered by the wind turbine rotor in $\left(\mathrm{m}^{2}\right), \mathrm{U}_{\mathrm{w}}$ is the wind speed in $\left(\mathrm{ms}^{-1}\right), \mathrm{C}_{\mathrm{p}}$ is the power coefficient of the wind turbine and $\lambda$ is the tip-speed ratio and is related to the rotor speed $\left(\omega_{m}\right.$ in $\left.\operatorname{rads}^{-1}\right)$ in as in Equation 2.

$$
\begin{gathered}
\lambda=\frac{\omega_{m} R}{U_{w}} \mathrm{Cp} \\
\mathrm{A}=2 \mathrm{RH}
\end{gathered}
$$

where $\mathrm{R}$ is turbine radius in $(\mathrm{m}), \mathrm{H}$ is the turbine height in (m). The power coefficient $C_{p}$ is given as a function of $\Theta$ (pitch angle of the turbine) and $\lambda$ (the tip-speed ratio). The value of $\mathrm{C}_{\mathrm{p}}$ can only go as high as 0.59 according to the Betz law $[6,7]$. The mechanical torque is related with mechanical power by Equation 4.

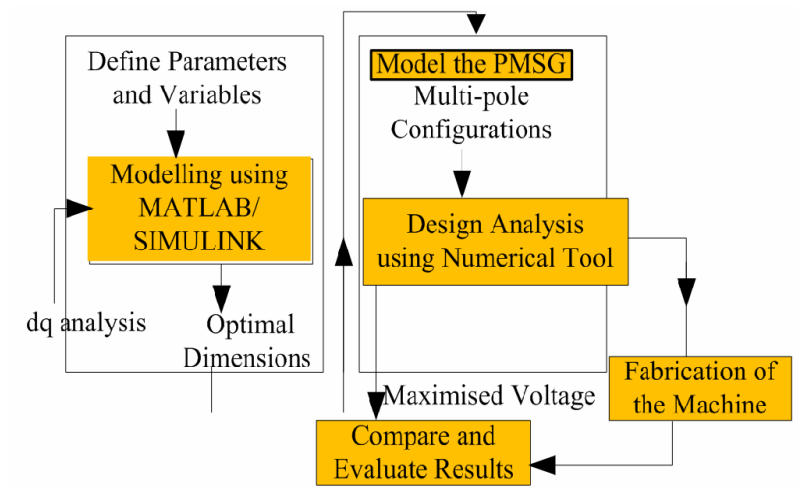

Figure 1. Methodology used in this design.

$$
\mathrm{T}_{\mathrm{m}}=\frac{\mathrm{P}_{\mathrm{m}}}{\omega_{\mathrm{m}}}
$$

Figure 2 shows the modeling and design of the turbine. For computation of the power coefficient, maximum power coefficient is at null pitch angle is 0.4412 [1]. Taking the value of $\mathrm{C}_{\mathrm{p}}$ as 0.4412 , air density as 1.225 , the above mentioned equations are used to calculate the swept area, mechanical power from the turbine and mechanical torque generated from it. Wind speed, radius and the height of the turbines are varied in the simulation to get optimal torque and power.

\subsection{Design of the Three Phases PMSG}

Axial Flux Permanent Magnet (AFPM) motor with its magnetic flux propagating at an axial direction from the magnets and are best suited for low wind speed [4-5] [12]. In comparison to the transverse flux design the axial flux design offers high torque and power density. Therefore the AFPM is considered for the development of this research work. The entire simulation is designed in terms of park transformation analysis that is a vector representation of three phase ac circuit models into a dq reference coordinates [10-13] as shown in Figure 3.

The park transform equation is given below:

$$
\left\lfloor\begin{array}{c}
\mathrm{f}_{\mathrm{q}} \\
\mathrm{f}_{\mathrm{d}} \\
\mathrm{f}_{\mathrm{\sigma}}
\end{array}\right\rfloor=\left[\begin{array}{ll}
\mathrm{T}_{\mathrm{gd} \sigma}
\end{array}\right]\left[\begin{array}{l}
\mathrm{f}_{\mathrm{a}} \\
\mathrm{f}_{\mathrm{b}} \\
\mathrm{f}_{\mathrm{c}}
\end{array}\right]
$$

Here, f can be current, voltage or flux .

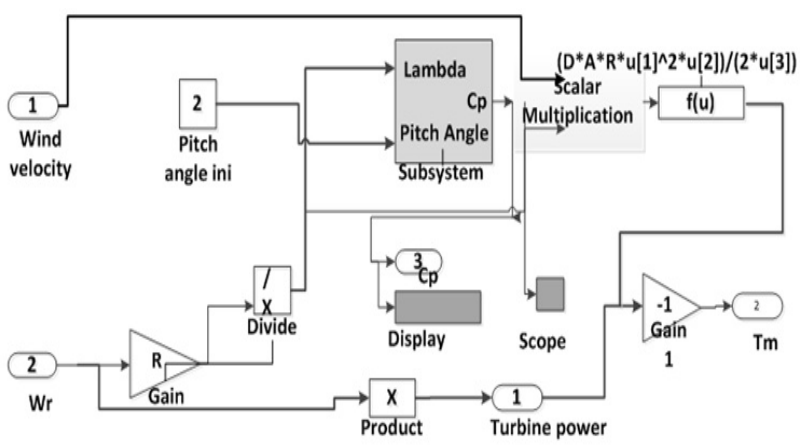

Figure 2. Modeling of turbine.

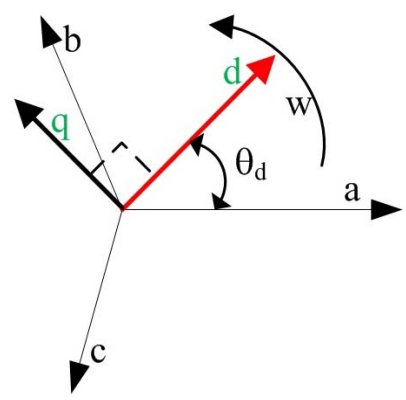

Figure 3. Park transform for generators. 
$\mathrm{T}_{\mathrm{dq} 0}$ is given by Equation 6 .

$$
\begin{aligned}
& {\left[T_{q d Q}\left(Q_{q}\right)\right]=} \\
& \frac{2}{3}\left[\begin{array}{ccc}
\cos \theta_{q} & \cos \left(\theta_{q}-\frac{2 \pi}{q}\right) & \cos \left(\theta_{q}+\frac{2 \pi}{q}\right) \\
-\sin \theta_{q} & -\sin \left(\theta_{q}-\frac{2 \pi}{8}\right) & -\sin \left(\theta_{q}+\frac{2 \pi}{8}\right) \\
\frac{1}{2} & \frac{1}{2} & \frac{1}{2}
\end{array} \mid\right.
\end{aligned}
$$

Here, $\theta_{\mathrm{q}}$ is the angular position. The coupling element between turbine and generator is described with Swing's equation which is stated at Equation 7 and Equation 8.

$$
\begin{gathered}
\mathrm{J} \frac{\mathrm{d}^{2} \mathrm{e}}{\mathrm{dt}^{2}}=\mathrm{T}_{\mathrm{m}-\mathrm{T}_{\mathrm{e}}}=\mathrm{T}_{\mathrm{a}} \\
\mathrm{T}_{\mathrm{a}}=\frac{\mathrm{dW}}{\mathrm{dt}}
\end{gathered}
$$

Here, $\mathrm{J}$ is the total moment of inertia of the rotor mass in $\mathrm{kgm}^{2}, \mathrm{~T}_{\mathrm{m}}$ is the mechanical torque in $\mathrm{Nm}, \mathrm{T}_{\mathrm{e}}$ is the electrical torque output of the generator in $\mathrm{Nm}, \mathrm{W}_{\mathrm{e}}$ is the mechanical speed of the rotor in (rpm) and $\theta$ is the angular position of the rotor in (rad). Voltage of PMSG in the $\mathrm{d}-\mathrm{q}$ axis is then expressed as in Equation 9 - Equation 10.

$$
\begin{gathered}
V_{q}=-\left(r+\mathrm{p} L_{q}\right) i_{q}-w_{\sigma} L_{d} i_{d}+w_{y} \lambda_{m} \\
V_{d}=-\left(r+\mathrm{p} L_{q}\right) i_{q}-w_{q} L_{q} l_{q}
\end{gathered}
$$

From the above assertions, the dynamic electrical model is shown as in Equation 11 - Equation 13.

$$
\frac{\mathrm{di}_{\mathrm{d}}}{\mathrm{dt}}=\frac{1}{\mathrm{~L}_{\mathrm{qs}}+\mathrm{L}_{\mathrm{ls}}}\left(-\mathrm{R}_{\mathrm{g}} \mathrm{l}_{\mathrm{q}}-\mathrm{W}_{\mathrm{g}}\left(\left(\mathrm{L}_{\mathrm{dd}}+\mathrm{L}_{\mathrm{ls}}\right) \mathrm{H}_{\mathrm{d}}+\lambda_{0}\right)+\mathrm{U}_{\mathrm{d}}\right)
$$

$$
\begin{aligned}
& L_{\mathrm{d}}=L_{\mathrm{ds}}+L_{\mathrm{ls}} \\
& \mathrm{L}_{\mathrm{q}}=\mathrm{L}_{\mathrm{qs}}+\mathrm{L}_{\mathrm{ls}}
\end{aligned}
$$

Here, $\mathrm{L}_{\mathrm{d}}, \mathrm{L}_{\mathrm{q}}$ and $\mathrm{L}_{\mathrm{ds}}, \mathrm{L}_{\mathrm{qs}}$ are the inductances and leakage inductances $(\mathrm{H})$ on the $\mathrm{d}$ axis and $\mathrm{q}$ axis respectively. $\mathrm{i}_{\mathrm{q}}, \mathrm{i}_{\mathrm{d}}$ and $\mathrm{U}_{\mathrm{q}}, \mathrm{U}_{\mathrm{d}}$ are the stator currents and voltages corresponding to the $\mathrm{d}$-axis and q-axis. $\mathrm{R}_{\mathrm{a}}$ is stator resistance $(\Omega), \lambda_{0}$ is the magnetic flux linkage $(\mathrm{Wb})$. Here,

$$
\mathrm{w}_{\Theta}=\mathrm{pw}
$$

Here, $\mathrm{p}$ is the number of poles [12]. The dq frame current is mentioned as follows [13]:

$$
\begin{aligned}
& \frac{\mathrm{d} \mathrm{d}_{\mathrm{d}}}{\mathrm{dt}}=\frac{-\mathrm{R}_{\mathrm{g}} \mathrm{d}_{\mathrm{d}}}{\mathrm{L}_{\mathrm{d}}}+\frac{\mathrm{w}_{\mathrm{g}} \mathrm{L}_{\mathrm{g}} \mathrm{J}_{\mathrm{g}}}{\mathrm{L}_{\mathrm{d}}}+\frac{\mathrm{U}_{\mathrm{d}}}{\mathrm{L}_{\mathrm{d}}} \\
& \frac{\mathrm{d} d_{\mathrm{q}}}{\mathrm{dt}}=\frac{-\mathrm{R}_{\mathrm{g}} !_{\mathrm{q}}}{\mathrm{L}_{\mathrm{q}}}+\frac{\mathrm{w}_{\mathrm{g}} \mathrm{L}_{\mathrm{d}} \mathrm{d}_{\mathrm{d}}}{\mathrm{L}_{\mathrm{q}}}+\frac{\mathrm{w}_{\mathrm{q}} \lambda_{\mathrm{q}}}{\mathrm{L}_{\mathrm{q}}}+\frac{\mathrm{U}_{\mathrm{q}}}{\mathrm{L}_{\mathrm{q}}}
\end{aligned}
$$

Figure 4 shows the equivalent circuit for $\mathrm{dq}$ axis where as Figure 5 represents the block diagram of three phase PMSG which is designed in Simulink.

The electromagnetic torque for generator [12]:

$$
\mathrm{T}_{\theta}=1.5 \mathrm{p}\left(\left(\mathrm{L}_{\mathrm{q}}-\mathrm{L}_{\mathrm{q}}\right) 1_{\mathrm{d}} 1_{\mathrm{q}}+1_{\mathrm{q}} \lambda_{0}\right)
$$

The stator resistance is taken as $14 \Omega$; inductance of both dq axes is used as $0.8 \mathrm{mH}$; flux linkage established by magnet is $0.175 \mathrm{~Wb}$ and mass inertia is considered to be $0.089 \mathrm{~kg} / \mathrm{m}^{2}$. The design is for 10 pole pairs and the friction factor is neglected. The rated power at load is considered to be $1.4 \mathrm{KW}$. An AC-DC rectifier is connected at the load terminal of the generator to convert the voltage and current to $\mathrm{DC}$ value. The inside subsystem part of the generator is given as in Figure 6. Table 1 gives the values of parameters used in the design. The optimal parameter for the generator is used for numerical analysis. Figure 7(a) show the design of the generator Figure 7(b) shows the fabricated generator.

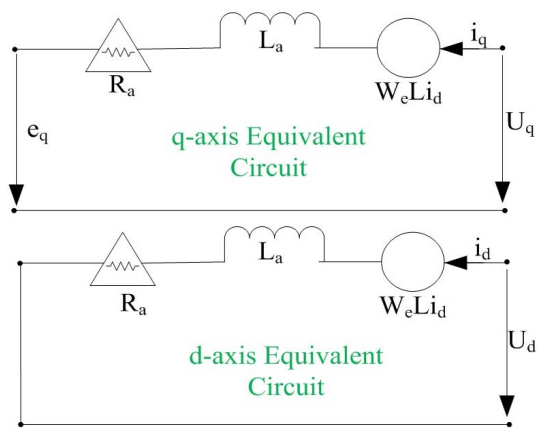

Figure 4. Equivalent q-axis and d-axis representation.

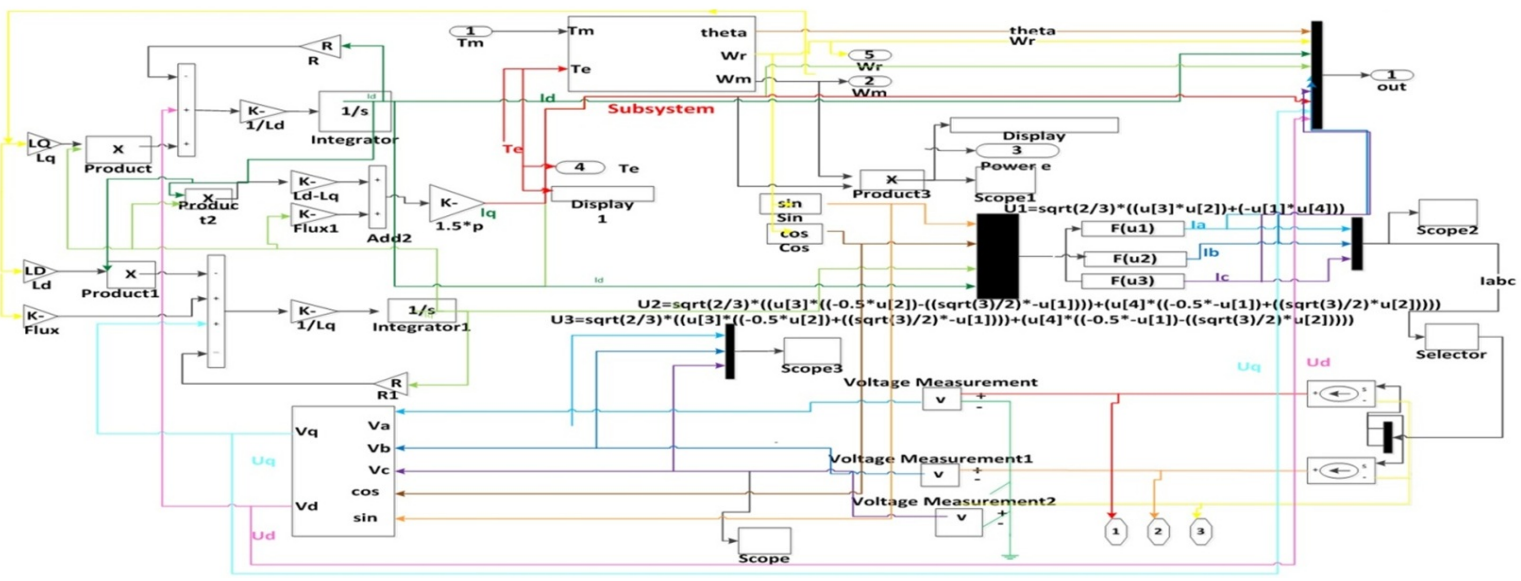

Figure 5. Modeling in Matlab/Simulink (Generator Part I). 


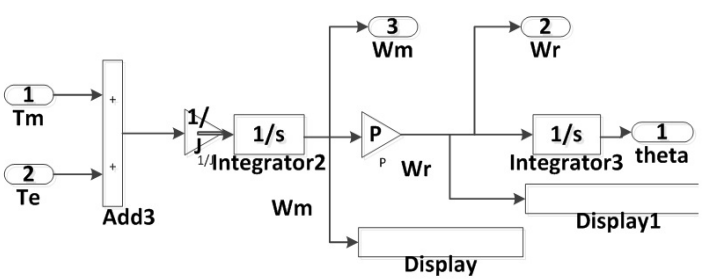

Figure 6. Subsystem (Generator Part II).

Table 1. Design Parameter.

\begin{tabular}{clc}
\hline Model & \multicolumn{1}{c}{ Parameter Name } & Value \\
\hline \multirow{4}{*}{ VAWT } & Air Density & $1.225 \mathrm{~kg} / \mathrm{m}^{3}$ \\
& Pitch Angle & 0 \\
& Power Coefficient & 0.4412 \\
& Wind Speed & $2 \mathrm{~m} / \mathrm{s}-7 \mathrm{~m} / \mathrm{s}$ \\
& Turbine Height & $1.6 \mathrm{~m}-2.6 \mathrm{~m}$ \\
& Turbine Radius & $1.6 \mathrm{~m}-2.6 \mathrm{~m}$ \\
& Stator Phase Resistance & $14 \mathrm{ohm}$ \\
& Inductance (d,q) & $0.8 \mathrm{mH}$ \\
& Flux Linkage & $0.175 \mathrm{~V} . \mathrm{s}$ \\
PMSG & Inertia & $0.089 \mathrm{~J}$ \\
& Pole Pair & 10 \\
& Rated Power & $1.5 \mathrm{KW}$ \\
& Nominal Frequency & $50 \mathrm{~Hz}$ \\
\hline
\end{tabular}

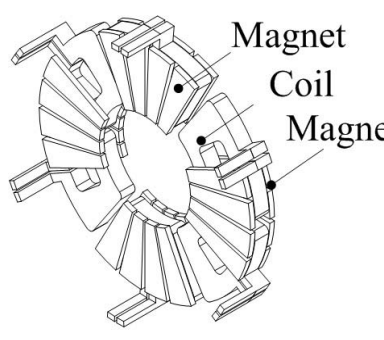

(a) Design Structure

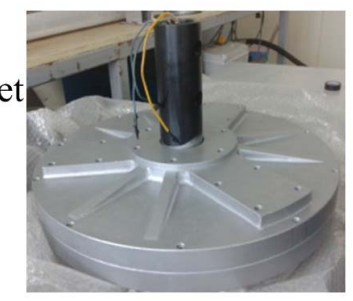

(b) Fabricated Model
Figure 7. PMSG at optimal values.

\section{Results and Discussion}

\subsection{Case 1 (Simulation of Turbine)}

In this part, simulation is performed to get torque and power for different values of radius and height keeping one parameter fixed at a time and compared with analytical values to verify the accuracy of design. Figure 8 shows the analytical and simulation comparison of mechanical torque for different swept areas while varying the radius of the turbine. The height is fixed at $2 \mathrm{~m}$. As it can be seen from Figure 7, analytical and simulation results are much closer to each other. This proves that the design of the turbine created in modeling is appropriate to work with. After taking consideration of different val- ues of turbine radius and height, it is observed from Figure 9 that at low wind speed, $0.8 \mathrm{~m}-1.2 \mathrm{~m}$ radius would be suitable for producing higher output power. However, the radius of the turbine is taken to be a fixed value of $1 \mathrm{~m}$. From Figure 10, it can be observed that the height between $2 \mathrm{~m}$ to $2.8 \mathrm{~m}$ is suitable to produce better output power. Therefore, the height of it is fixed at $2.6 \mathrm{~m}$.

\subsection{Case 2 (PMSG connected to VAWT)}

The stator resistance, inductance at dq frame, flux linkage, mass inertia and pole pairs are varied and a set of realistic parameter values are fixed (given in Table 1) in which the voltage and current were satisfactory to produce power. The power is increased with the increase in the number of pole and for practical consideration the

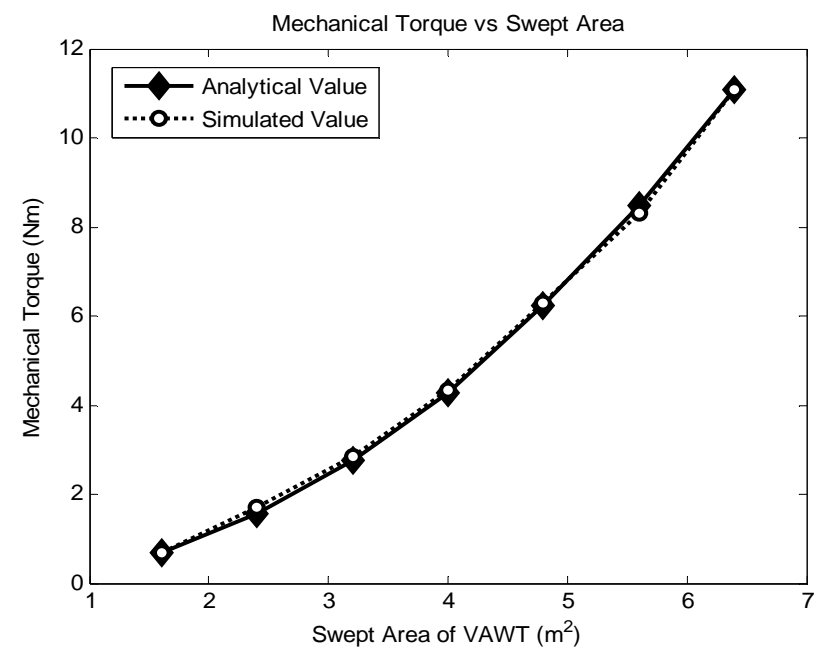

Figure 8. Mechanical Torque- Swept Area curve.

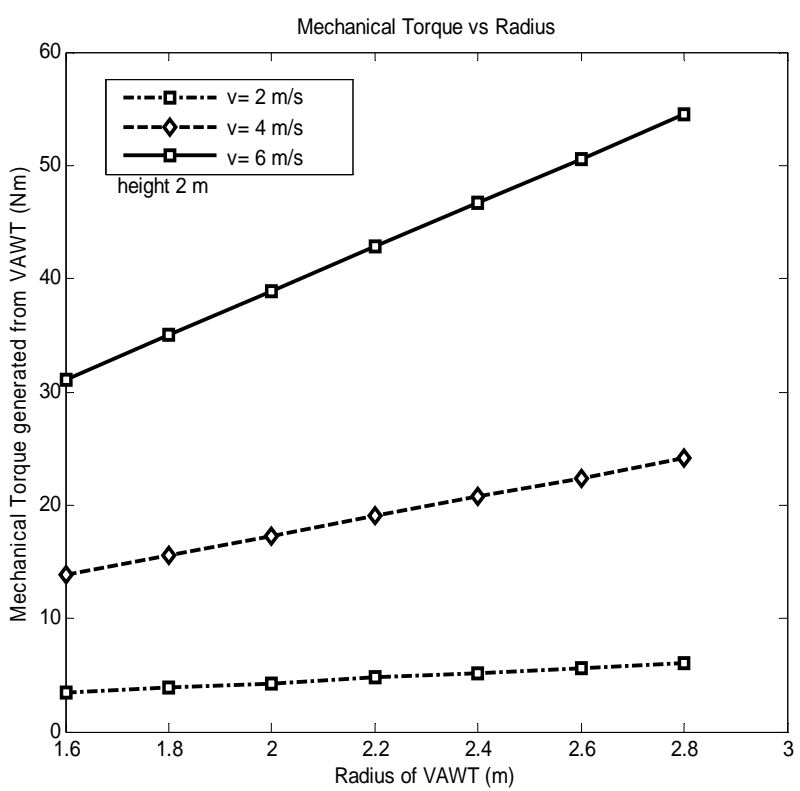

Figure 9. Torque generated for different radius. 
number of pole pair is fixed at 10. Figure 11 evolved by changing the mechanical torque for different wind speed and keeping the generator parameter fixed at optimal value. The load power is measured to make sure that the generator is able to produce adequate output power for a range of torque at low wind speed.

\subsection{Case 3 (Hardware Testing)}

The developed generator is experimentally tested at laboratory and the results are compared with that of the simulation value. Figure 12 - Figure 14 shows theoretical and experimental comparisons for a fixed wind speed of $6 \mathrm{~m} / \mathrm{s}$. Wind speed is taken as high value in order to investigate the difference in value accurately.

The experimental values are quite identical with simulation indicating the accuracy of the simulation design. The simulation power values for different speed and mechanical torque are higher than experimental values. This is due to power loss for friction factor as it is neglected in the simulation.

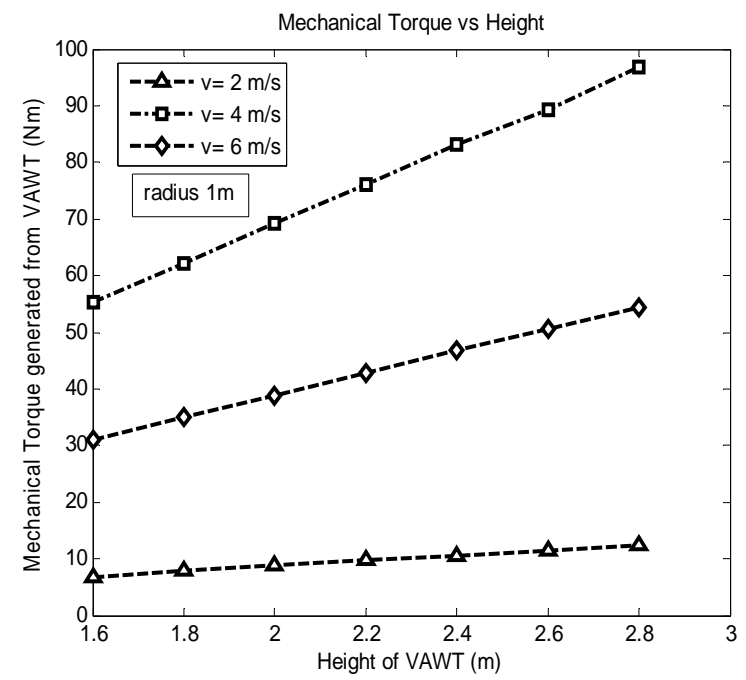

Figure 10. Torque generated for different heights.

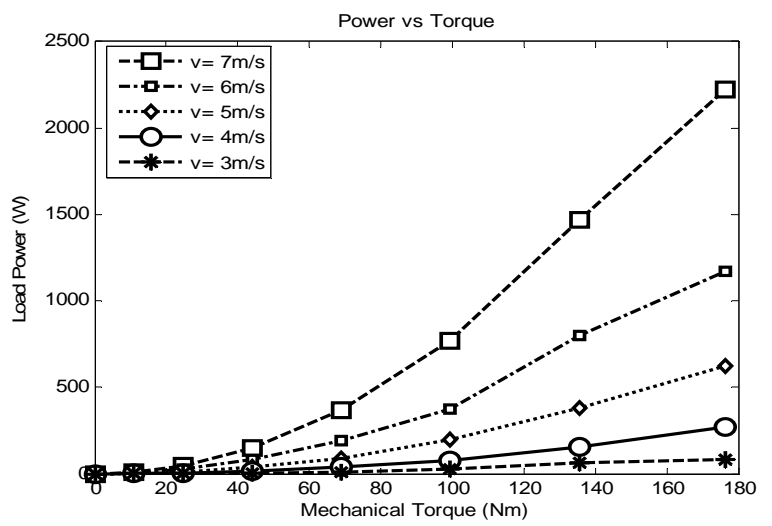

Figure 11. Graph of Power values at the load for different mechanical torque.

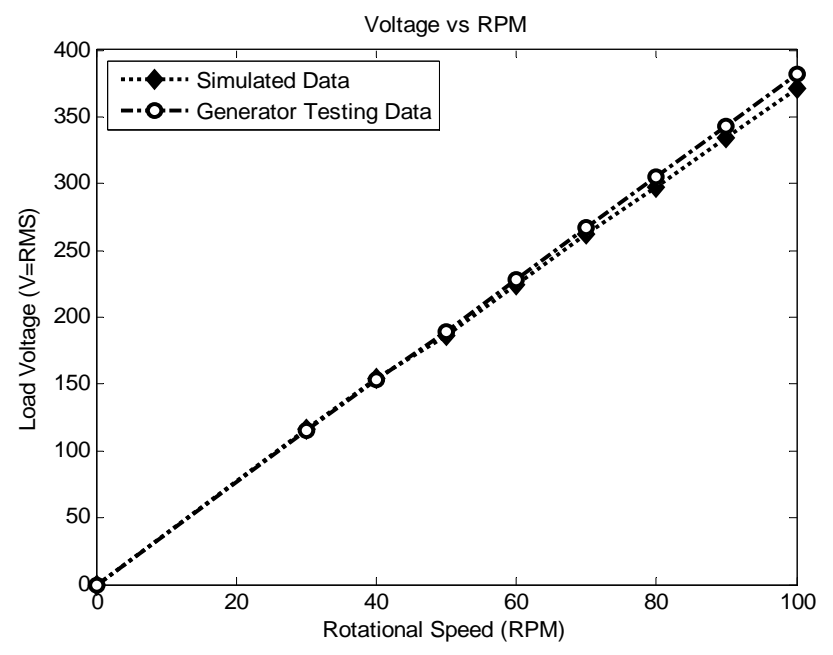

Figure 12. Voltage- Rotational Speed (RPM) curve.

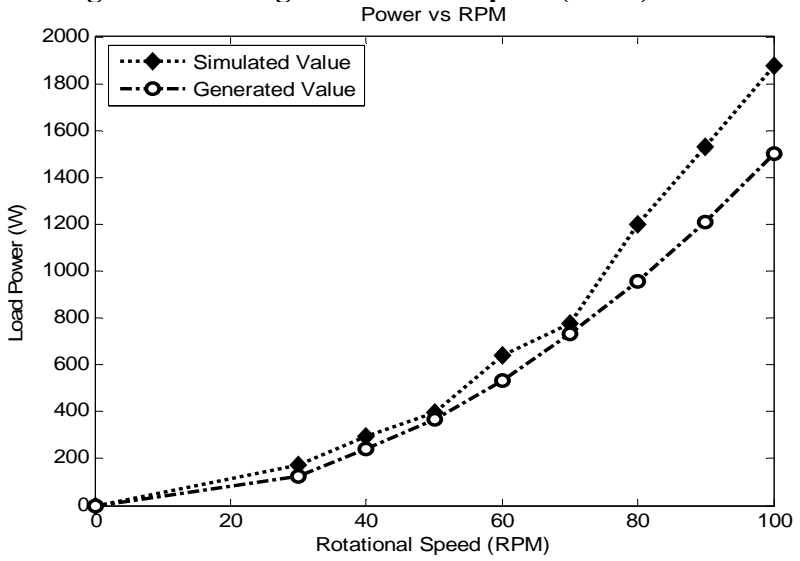

Figure 13. Power- Rotational Speed (RPM) curve.

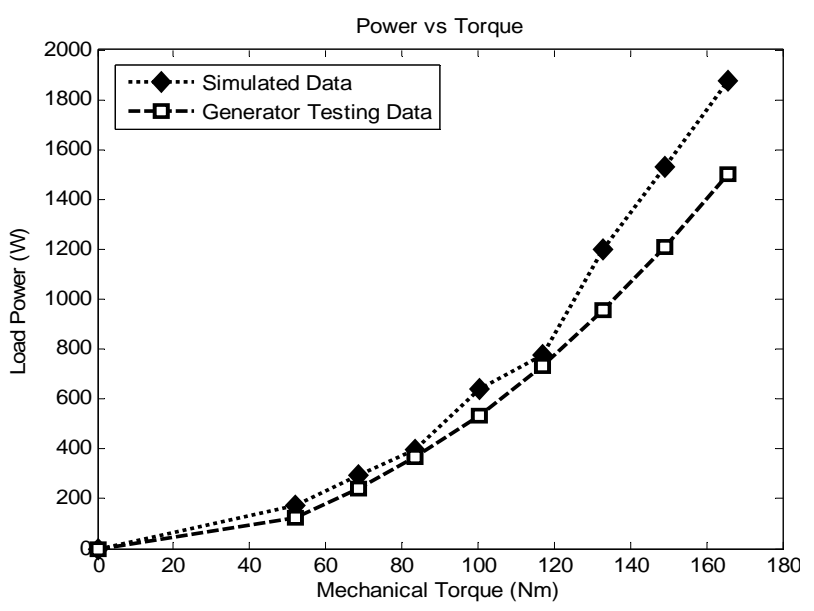

Figure 14. Power- Torque curve.

\section{Conclusions}

An optimal system is built for low level wind speed. The VAWT simulation produces torque and power with an estimated error of ion ranging from $0.05 \%-10 \%$ according to Table 2. After running several stages of simulation, 
the swept area is

Table 2. Error Estimation of VAWT.

\begin{tabular}{|c|c|c|c|}
\hline \multirow{2}{*}{$\begin{array}{c}\text { Swept Area } \\
{\left[\mathrm{m}^{2}\right]}\end{array}$} & \multicolumn{2}{|c|}{ Mechanical Torque [Nm] } & \multirow{2}{*}{$\begin{array}{c}\text { Error } \\
{[\%]}\end{array}$} \\
\hline & Theoretical & Simulation & \\
\hline 1.6 & 0.68 & 0.7 & 2.9 \\
\hline 2.4 & 1.557 & 1.7 & 9.18 \\
\hline 3.2 & 2.76 & 2.84 & 2.9 \\
\hline 4 & 4.29 & 4.324 & 0.8 \\
\hline 4.8 & 6.226 & 6.3 & 1.18 \\
\hline 5.6 & 8.474 & 8.3 & 2.05 \\
\hline 6.4 & 11.069 & 11.074 & 0.05 \\
\hline
\end{tabular}

Table 3. Error Estimation of PMSG.

\begin{tabular}{|c|c|c|c|}
\hline \multirow{2}{*}{ MechanicalTorque(Nm) } & \multicolumn{2}{|c|}{ Load Power } & \multirow{2}{*}{ Error (\%) } \\
\hline & Simulation & Experimental & \\
\hline 52 & 148 & 126 & 14.90 \\
\hline 68.6 & 284 & 240 & 15.49 \\
\hline 83.4 & 416 & 367 & 11.81 \\
\hline 100.2 & 586 & 534 & 8.81 \\
\hline 116.9 & 817 & 733 & 10.23 \\
\hline 132.9 & 1004 & 956 & 4.79 \\
\hline 149.2 & 1262 & 1209 & 4.19 \\
\hline 165.8 & 1878 & 1500 & 20.13 \\
\hline
\end{tabular}

fixed at $5.2 \mathrm{~m}^{2}$ having fixed the radius and height of the turbine to $1 \mathrm{~m}$ and $2.6 \mathrm{~m}$ respectively. For the generator part, the simulation data is gathered for different values of torque from the turbine; the design is built in CFD and sent to a manufacturing company. Upon arrival, the generator is tested and load voltage and power were measured for different set of values of RPM and Torque. As it can be seen in Table 3, there were differences while calculating the error $(5 \%$ - $27 \%)$ for load power. It is due to the friction factor and stator inductance difference. This VAWT with PMSG can make a significant impact for low level wind situation in which Malaysia and so many other countries stand.

\section{Acknowledgements}

The project is funded by the Ministry of Higher Education (MOHE) of Malaysia under the ERGS grant.

\section{REFERENCES}

[1] Zaharim, S. K. Najid, A. M. Razali and K. Sopian "Wind Speed Analysis in the East Coast of Malaysia," European Journal of Scientific Research, Vol. 32, No. 2, 2009, pp.
208-215.

[2] R. Bharanikumar, A. C. Yazhini and N. Kumar, "Modelling and Simulation of Wind Turbine Driven Permanent magnet Generator with New MPPT Algorithm," Asian Power electronics journal, Vol. 4, 2012.

[3] W. Fei and P. I. Luk, "A New Technique of Cogging Torque Suppression in Direct-Drive Permanent-Magnet Brushless Machines," IEEE Transactions on Industry Applications, Vol. 46, No.4, 2010,pp. 1332-1340. doi:10.1109/TIA.2010.2049551

[4] P. C. Krause, O. Wasynczuk and S. D. Sudho. "Analysis of Electric Machinery and Drive Systems," Wiley \& Sons, 2002. doi:10.1109/9780470544167

[5] C. V. Aravind, Rajparthiban, Rajprasad and Y. V. Wong "A Novel Magnetic Levitation Assisted Vertical Axis Wind Turbine- design and Procedure," IEEE Colloquium on Signal Processing and its Applications, Melacca, Malaysia CSPA 2012

[6] J A.M. De Broe, S. Drouilllet and V. Oevorglan, "A Peak power Tracker for Small Wind Turbines in Battery Charging Applications," IEEE Transactions on Energy Conv., Vol. 14, No. 4, Dec. 1999, pp. 1630-1635. doi: $10.1109 / 60.815116$

[7] J. D. M. Whaley, W. L. Soongand and N. Ertugrul, "Investigation of Switched-Mode Rectifier for Control of Small-Scale Wind Turbines," Intl' Conference Proceed. of IEEE-IAS Annual Meeting, Vol. 4, 2005, pp. 2849-2856.

[8] S. Belakehal, H. Benalla and A. Bentounsi, "Power Maximization of Small Wind System using Permanent magnet Synchronous Generator" Revue des energies Renouvelables, Vol. 12, No. 2 ,2009, pp. 307-319.

[9] J. G. SIootweg, H. Pollnder and W. L. Kling, "Representing Wind Turbine Electrical Generating Systems in Fundamental Frequency Simulations," IEEE Trans. Energy Convr, Vol. 18, No. 4, Dec. 2003, pp. 516-524.

[10] A. G. Westlake, J. R. Bumby and E. Spooner, "Damping the Power-angle Oscillations of a Permanent Magnet Synchronous Generator with Particular to Wind Applications," Proc. Ekct. Power Appl., Vol. 143, No. 3, May1996, pp. 269-280. doi:10.1049/ip-epa:19960285

[11] C. Busca, A. Stan, T. Stanciu and D. I. Stroe "Control of Permanent Magnet Synchronous of Large Wind Turbines," Denmark : Departament of Energy Technology: Aalborg University, November 2010, Industrial Electronics (ISIE), pp. 3871-3876.

[12] M. Yin, G. Y. Li, M. Zhou and C. Y. Zhao, "Modeling of the Wind Turbine with a Permanent Magnet Synchronous Generator for Integration," Power Engineering Society General Meeting, 2007, pp.1-6.

[13] K. Tan and S. Islam, "Optimum Control Strategies in Energy Conversion of PMSG Wind Turbine System without Mechanical Sensors," Energy Conversion, IEEE Transactions on, Vol. 19, No. 2, June 2007, pp. 392- 399. doi:10.1109/TEC.2004.827038 